\title{
Comparative study of surgically induced astigmatism: superior versus superotemporal scleral incision performed in rural hospital
}

\author{
Kripalini S. H. ${ }^{1}$ \\ ${ }^{1}$ Dr Kripalini Soonthodu Hoovayya, Assistant Professor, Department of Ophthalmology, K.V.G Medical College and \\ Hospital, Sullia, Karnataka, India.
}

Corresponding Author: Dr. Jnanamurthy, Senior Specialist, District Hospital, Shimoga, Karnataka. E-mail: drjanardhanang@gmail.com

\begin{abstract}
Introduction: Phacoemulsification has become a gold standard procedure of cataract extraction in the developed countries. Phacoemulsification is expensive hence manual small incision cataract surgery is a better alternative in developing nations. One of the important cause of poor uncorrected visual activity after cataract extraction is high astigmatism. Incision being the first and most important determinant of postoperative astigmatism. Placement of incision superotemporally is one modification to minimize the high pre-existing ATR astigmatism and improving the postoperative visual outcome. Aim: To study the type and amount of surgically induced astigmatism following superior and superotemporal scleral incision in manual small incision cataract surgery. Design: Prospective randomized comparative clinical study. Methodology: 50 eyes of 50 patients each were randomly assigned for superior scleral incision and superotemporal scleral incision and MSICS with PCIOL implantation were performed. Patients were examined on day 1, day 7, end of 4 weeks and 3 months after surgery. Results: 3 months after surgery, $80 \%$ of the patients in superior incision group had ATR astigmatism and $86 \%$ of the patients in super temporal incision group had WTR astigmatism. The mean SIA in superotemporal group was significantly less than superior incision group. Conclusion: MSICS performed with superotemporal scleral incision in comparison with superior scleral incision produces significantly less surgically induces astigmatism with better stabilization of refraction.
\end{abstract}

Key words: Astigmatism; MSICS; superotemporal incision; Superior incision; Surgically induced astigmatism; cataract.

\section{Introduction}

Corneal astigmatism is associated with cataract surgery since the first limbal incision was made. Recent progress in cataract surgery had heightened patient expectations of outcomes. Nowadays good postoperative vision without spectacles is considered the norm. Thus control of postoperative astigmatism is key to achieve these goals [1].

Over the years, a better understanding of different preoperative and intra-operative determinants of surgically induced astigmatism has made it possible to actually plan out the surgical intervention and their modifications according to preoperative state of astigmatism of the patient in order to achieve minimum possible postoperative astigmatism [2]. The purpose of modern cataract surgery is not only cataract extraction and Intraocular lens (IOL) implantation but also to

Manuscript received: $5^{\text {th }}$ May 2019

Reviewed: $15^{\text {th }}$ May 2019

Author Corrected: $20^{\text {th }}$ May 2019

Accepted for Publication: $23^{\text {rd }}$ May 2019
Reduce or rectify existing refractive error or astigmatism. Preexisting astigmatism is present in over $60 \%$ of all patients scheduled for cataract surgery [3]. In order to achieve the reduction of post-operative astigmatism, instrumentation and surgical techniques have been constantly upgraded. Phacoemulsification is the gold standard for cataract surgery in developed countries. In developing countries like India it is limited to cities and institutions. Manual small incision cataract surgery (MSICS) by virtue of its self-sealing sutureless technique, low cost of instrumentation and disposables is suited for rural population of India $[4,5,6]$.

Many variables exist in creation of the wound for the cataract surgery, like direction (superior, temporal or oblique), location (corneal versus scleral), depth, width and shape. The refinement and evolution of manual small incision cataract surgery have diminished controversies regarding the shape and width of incisions, and the depth of incision has been described 
to have little influence on the amount of surgically induced astigmatism [2]. It has also been reported that the direction and location of the wound can still have a significant influence on surgical outcome [7].

Thus we conducted this study to evaluate the amount and type of surgically induced astigmatism in superior and superotemporal scleral incision in manual small incision cataract surgery. There were no similar studies done in rural hospital setting of India.

\section{Materials and Methods}

Following due permission from the Hospital Ethics Committee and written informed consent from patients this, prospective, randomized, clinical study was conducted in 100 patients posted for Manual Small Incision Cataract Surgery (MSICS) with Intra Ocular Lens (IOL) implantation in rural hospital attached to K.V.G. Medical College, Sullia, Karnataka. All the Surgeries were conducted by single surgeon between April 2016-March 2017

Inclusion criteria: Patients aged between 40 to 90 years, of either sex who were clinically diagnosed with senile cataract, (mature/immature).

Exclusion criteria: Patients with corneal surface irregularities or opacities, glaucoma, uveitis, traumatic cataract, hard cataract, patients on steroid and any previous intraocular surgeries.

Informed consent was taken from all the patients prior to the surgery. On the previous day of surgery patients were advised to instill antibiotic drops and xylocaine test dose was given. Patients were randomly allocated to one of the two groups (50 each) by computer-generated random list which were delivered in sequentially numbered opaque sealed envelopes.

Group SI: patients underwent SICS through superior scleral incision with implantation of IOL.

Group STI: patients underwent SICS through superotemporal scleral incision with implantation of IOL.

On the day of surgery, both upper and lower lid lashes were trimmed and the eye to be operated upon was dilated using tropicamide $(0.8 \%)$ and phenylephrine (5\%) eye drops, 1 drop every 10-15 minutes starting one hour prior to surgery till full dilatation. One drop of Flurbiprofen $(0.03 \%)$ was instilled to prevent miosis and as a prophylaxis for prevention of cystoid macular edema. Under all aseptic precautions, MSICS with PC (Posterior Chamber) IOL fixation was done under peribulbar anaesthesia. After the application of superior rectus bridle suture.

In Group SI: Fornix based conjunctival flap was taken between 10 O'clock and 2 O'clock down to bare sclera. Gentle cautery was done and a straight scleral incision of about $6.5 \mathrm{~mm}$ was placed $2 \mathrm{~mm}$ behind the limbus using 11 No. B.P blade. Side port was made at 10 or 2 O'clock position.

In Group STI: Fornix based conjunctival flap was taken from 12 O'clock to 3 O'clock. Gentle cautery was done and $6.5 \mathrm{~mm}$ scleral straight incision was placed around 1-1.5 mm posterior to limbus using 11 No. B.P blade. Side port was made around 3 clock hours away from the main port Dissection of sclero corneal tunnel was undertaken with beveled up crescent blade up to $1 \mathrm{~mm}$ inside the clear cornea. Anterior capsule was stained with trypan blue.

Viscoelastic was then introduced into anterior chamber and continuous curvilinear capsulorrhexis was done through the side port. Anterior chamber entry was done through the main port using $3.2 \mathrm{~mm}$ keratome and incision was extended laterally. The internal opening was made 1-2 mm larger than the external opening.

Thorough hydro dissection was done using 30-gauge cannula and nucleus was prolapsed into the anterior chamber. Delivery of the nucleus done with sandwich technique using Vectis and Sinskey hook. Anterior chamber was maintained throughout the procedure by injecting viscoelastic into anterior chamber.

After delivering the nucleus, remaining cortex was aspirated using Simcoe cannula, sub incisional cortex was aspirated through side port. A posterior chamber polymethylmethacrylate IOL of $6 \mathrm{~mm}$ (overall $12.5 \mathrm{~mm}$ ) optics was inserted in the bag and remaining viscoelastic was removed.

Anterior chamber was reformed with balanced salt solution through side entry and sealed by stromal hydration. Main wound was checked for any leakage then conjunctiva is closed using cautery, sub conjunctival injection of dexamethasone and gentamycin was given and eye was patched. Any case requiring the suturing of the tunnel or side port was excluded from the study.

Post-operative work up: Post-operative treatment included topical antibiotic and steroid combination for a 
week followed by only topical steroid drops in a tapering dose for next 4 wks. Patients were examined on 1st postoperative day, 1 week, 4 weeks and 3 months after surgery for keratometry readings and visual acuity.

For simplification of analysis all astigmatic changes were studied only in the horizontal and vertical meridian.
Statistical Analysis: The categorical data were represented as numbers and percentages. The data collected were analysed for normal distribution by oneway analysis (and were normally distributed). The analysis was performed using the statistical package SPSSv19.0 [IBM India Pvt Ltd, Bangalore, India]. Statistical significance was considered when the p-value was $<0.05$.

\section{Results}

In our study, 100 eyes were operated upon for cataract by MSICS. 50 eyes were operated using superior scleral incision and 50 by superotemporal scleral incision. Both the groups were comparable with respect to age, sex, preoperative astigmatism [Table 1] Follow up was 100\%.

Table-1: Demographic data.

\begin{tabular}{|c|c|c|c|}
\hline & Group SI & Group STI & P value \\
\hline $\begin{array}{c}\text { Age in years } \\
\text { Mean } \pm \text { SD* }\end{array}$ & $63.96 \pm 12.66$ & $64.03 \pm 10.25$ & $\mathrm{p}>0.05$ \\
\hline $\begin{array}{c}\text { Sex ratio } \\
\text { Male: Female }\end{array}$ & $28: 22$ & $27: 23$ & $\mathrm{p}>0.05$ \\
\hline
\end{tabular}

*Standard Deviation

Table-2: Preoperative Astigmatism.

\begin{tabular}{|c|c|c|c|}
\hline Type of astigmatism & Group SI & Group STI & Total \\
\hline With The Rule & $21(42 \%)$ & $17(34 \%)$ & $38(38 \%)$ \\
\hline Against The Rule & $19(38 \%)$ & $23(46 \%)$ & $42(42 \%)$ \\
\hline No Astigmatism & $10(20 \%)$ & $10(20 \%)$ & $20(20 \%)$ \\
\hline Total & 50 & 50 & 100 \\
\hline
\end{tabular}

In our study, $38 \%$ of the patient had pre-operative with the rule astigmatism, $42 \%$ of the patient had pre-operative against the rule astigmatism and $20 \%$ had no astigmatism. [Table 2]

Table-3: Post operative astigmatic change in patients with preoperative With the Rule (WTR) astigmatism.

\begin{tabular}{|c|c|c|c|c|c|}
\hline $\begin{array}{c}\text { Type of incision } \\
\text { (no. of cases) }\end{array}$ & $\begin{array}{c}\text { Post-operative } \\
\text { astigmatic change }\end{array}$ & $\mathbf{1}^{\text {st }}$ Day & $\mathbf{7}^{\text {th }}$ Day & 4 Weeks & 3 Months \\
\hline \multirow{3}{*}{ Group SI (21) } & Increased & 14 & 5 & 5 & 5 \\
\cline { 2 - 6 } & Decreased & 3 & 13 & 14 & 14 \\
\hline \multirow{2}{*}{ Group STI (17) } & Same & 4 & 3 & 2 & 14 \\
\cline { 2 - 6 } & Increased & 8 & 14 & 14 & 2 \\
\hline \multicolumn{2}{|c|}{ Chi Square test (x2) } & 4 & 2 & 1 & 1 \\
\hline
\end{tabular}

It was observed that, on the $1^{\text {st }}$ postoperative day superior incision group had more WTR astigmatism than in superotemporal incision group. Further in superior incision group, there was a decrease in the amount of WTR astigmatism from $1^{\text {st }}$ postoperative day till the end of 3 months. In superotemporal incision group there was an increase in the amount of WTR astigmatism [Table 3]. 
Table-4: Post operative astigmatic change in patients with preoperative ATR astigmatism.

\begin{tabular}{|c|c|c|c|c|c|}
\hline $\begin{array}{c}\text { Type of incision } \\
\text { (no. of cases). }\end{array}$ & $\begin{array}{c}\text { Post-operative } \\
\text { astigmatic change }\end{array}$ & $1^{\text {st }}$ Day & $7^{\text {th }}$ Day & 4 Weeks & 3 Months \\
\hline \multirow{3}{*}{ Group SI (19) } & Increased & 15 & 14 & 12 & 13 \\
\hline & Decreased & 1 & 2 & 3 & 3 \\
\hline & Same & 3 & 3 & 4 & 3 \\
\hline \multirow{3}{*}{ Group STI (23) } & Increased & 9 & 2 & 1 & 1 \\
\hline & Decreased & 11 & 18 & 19 & 19 \\
\hline & Same & 3 & 3 & 3 & 3 \\
\hline \multicolumn{2}{|c|}{ Chi Square test } & 9.539 & 17.78 & 16.35 & 16.35 \\
\hline \multicolumn{2}{|c|}{$\mathrm{p}$ Value } & $<0.05$ & $<0.05$ & $<0.05$ & $<0.05$ \\
\hline
\end{tabular}

On the first post-operative day, there was a statistically significant difference between both the groups with respect to ATR astigmatism. In superior incision group the ATR astigmatism decreased from 15 to 13 patients by the end of 3 months. Whereas in superotemporal group there was rapid decrease from 9 to 1 patients by the end of $7^{\text {th }}$ postoperative day and remained same after 3 months [Table 4].

Table-5: Type of post-operative Astigmatism.

\begin{tabular}{|c|c|c|c|}
\hline Type of post op astigmatism & SI & STI & Total \\
\hline With The Rule & $9(18 \%)$ & $43(86 \%)$ & 45 \\
\hline Against The Rule & $40(80 \%)$ & $5(10 \%)$ & 3 \\
\hline No Astigmatism & $1(2 \%)$ & $2(4 \%)$ & 100 \\
\hline Total & 50 & 50 & 52 \\
\hline
\end{tabular}

In our study, superior incision caused more ATR shift than the WTR, where as in temporal incision group the shift was more towards WTR [Table 5].

Table-6: Mean Surgically Induced Astigmatism.

\begin{tabular}{|c|c|c|c|c|}
\hline $\begin{array}{c}\text { SIA } \\
\text { (in Diopters) }\end{array}$ & $\begin{array}{c}\text { SI } \\
\left(\text { Mean }+\mathbf{S D}^{\dagger} \text { ) }\right.\end{array}$ & $\begin{array}{c}\text { STI } \\
(\text { Mean }+ \text { SD) }\end{array}$ & 't' & p value \\
\hline $1^{\text {st }}$ day & $2.41 \mathrm{D}^{*}+1.275$ & $1.36 \mathrm{D}+0.890$ & 4.760 & $<0.001$ \\
\hline $7^{\text {th }}$ Day & $1.335 \mathrm{D}+0.911$ & $1.19 \mathrm{D}+0.99$ & 2.758 & $<0.05$ \\
\hline 4 weeks & $1.00 \mathrm{D}+0.696$ & $0.70 \mathrm{D}+0.384$ & 2.672 & $<0.05$ \\
\hline 3 months & $0.94 \mathrm{D}+0.670$ & $0.61 \mathrm{D}+0.694$ & 2.33 & $<0.05$ \\
\hline
\end{tabular}

*Diopters, ${ }^{\dagger}$ Standard Deviation

In the present study, it was observed that superior incision group showed more mean surgically induced astigmatism $(2.41 \mathrm{D}+1.275)$ on the first day compared to temporal incision group $(1.36 \mathrm{D}+0.890)$ which was statistically highly significant. On the 7th day there was further reduction in the mean SIA in both the groups, by the end of 3 months there was further decrease in mean surgically induced astigmatism but the difference between two groups was still found to be statistically significant [Table 6].

\section{Discussion}

Astigmatism following cataract surgery is a known complication from the time when cataract surgery was started. Various factors like incision size, its location, its techniques and suture material influences the postoperative astigmatism. A sutureless cataract surgery eliminates the effects of placement of suture and suture 


\section{Original Research Article}

materials on the post-operative astigmatism. Although phacoemulsification remains the gold standard technique the cost effectiveness, shorter learning curve makes manual small incision cataract a better alternative. It gives visual results which are comparable to phacoemulsification, at low cost. Further it is suitable for mass surgeries (camp) and appropriate for developing countries like India [8]. But large size incision causes increased rates of astigmatism. High astigmatism is the leading cause of poor uncorrected visual acuity following cataract surgery [9]. In view of these findings, this study was undertaken with the aim to evaluate the type and amount of SIA between superior scleral incision and temporal scleral incision in a rural hospital setting.

In our study out of the 100 patients undergoing MSICS, 42 patients had ATR, 38 patients had WTR and 20 patients had no astigmatism. This shows that ATR is the commonest type of astigmatism in patients undergoing cataract surgery. This is similar to study by Gokhale et al and Yadav et al $[10,11]$. In Jaffe's study of 1557 eyes, he recorded $30 \%$ with the rule astigmatism, $42.5 \%$ against the rule astigmatism, $1.7 \%$ oblique against the rule astigmatism and no astigmatism was found in 25.8 $\%$ of the patients [9]. Reason behind this might be that in normal healthy eyes, upper tarsal plate is stiff which causes pressure on cornea leading to with the rule astigmatism but as age advances this pressure gradually decreases resulting in against the rule astigmatism.

The results of our study are consistent with previous reports $[10,12,13]$ that superior incision causes more ATR shift than the WTR. This may be due to the fact that the incision on the superior meridian causes flattening of the vertical meridian and steepening of the horizontal meridian leading to more ATR shift post operatively.

Where as in superotemporal incision the shift of astigmatism was more towards WTR, this is because the superotemporal incision causes flattening of horizontal meridian and steepening of the vertical meridian leading to more WTR shift. This may be advantageous as most of the elderly patients will have ATR astigmatism.

In the present study, there was a significant difference in the amount of astigmatism between both the groups on the first post-operative day. The astigmatism gradually reduced in both the group. However, after 4 weeks not much reduction was noted in both groups that is in SI group, there was only $0.06 \mathrm{D}$ change in the amount of astigmatism, where as in STI group the reduction of astigmatism was only 0.09 D. This shows that most of astigmatic stabilization occurred by 4 weeks and after that amount of variation is negligible and this may be the best time for prescribing spectacle correction.

\section{Conclusion}

Manual small incision cataract surgery can be placed either superiorly or superotemporally depending upon preoperative keratometric astigmatism. Superotemporal incision provide better vision because of less surgically induced astigmatism. Modification in placing the incision produces almost equivalent results to advanced procedures and hence provide better surgical outcome in limited resources setting.

\section{What this study adds to existing knowledge?}

In resource limited setting, manual small incision cataract surgery with superotemporal incision produce less surgically induced astigmatism and provide better post-operative visual outcome.

Funding: Nil, Conflict of interest: Nil

Permission from IRB: Yes

\section{References}

1. Akura J, Kaneda S, Hatta S, et al. Controlling astigmatism in cataract surgery requiring relatively large self-sealing incisions. J Cataract Refract Surg. 2000 Nov;26(11):1650-9.

2. Rathore MK, Temporal Tunnel Incision in SICS, In: Kamaljeet Singh. Small incision cataract surgery (phaco manual). $1^{\text {st }}$ Edition. Jaypee brothers; 2002: 136-9.

3. Oshika T, Sugita G, Tanabe T, et al. Regular and irregular astigmatism after superior versus temporal scleral incision cataract surgery. Ophthalmology. 2000 Nov; 107(11):2049-53.

4. Zawar SV, Gogate P. Safety and efficacy of temporal manual small incision cataract surgery in India. Eur J Ophthalmol. 2011 Nov-Dec;21(6):748-53. doi: 10.5301/ EJO. 2011.6521.

5. Khanna R, Pujari S, Sangwan V. Cataract surgery in developing countries. Curr Opin Ophthalmol. 2011 Jan; 22 (1): 10-4. doi: 10.1097/ICU.0b013e3283414f50.

6. Pershing S, Kumar A. Phacoemulsification versus extracapsular cataract extraction: where do we stand? Curr Opin Ophthalmol. 2011Jan; 22(1):37-42. doi:10. 1097 / ICU. 0b013e3283414fb3. 
7. Ruit S, Tabin G, Chang D, et al. A prospective randomized clinical trial of phacoemulsification vs manual sutureless small-incision extracapsular cataract surgery in Nepal. Am J Ophthalmol. 2007 Jan;143 (1): 32-38. Epub 2006 Sep 5. DOI:10.1016/j.ajo. 2006. 07.023

8. Gogate P, Deshpande M, Nirmalan PK. Why do phacoemulsification? Manual small-incision cataract surgery is almost as effective, but less expensive. Ophthalmology. 2007 May; 114 (5): 965-8. Epub 2007 Feb 12. DOI:10.1016/j.ophtha.2006.08.057

9. Jaffe N S, Jaffe M S and Jaffe G F, Intraocular lens, In: Cataract surgery and its complications. $6^{\text {th }}$ Edition. St Louis Missouri: Mosby; 1997. 147-99.

10. Gokhale NS, Sawhney S. Reduction in astigmatism in manual small incision cataract surgery through change of incision site. Indian J Ophthalmol. 2005 Sep;53(3):201-3.

11. Yadav H, Rai V. A Study of Comparison Astigmatism Following Manual Small Incision Cataract Surgery: Superior versus Temporal Approach. Journal of Evolution of Medical and Dental Sciences. 2014; 3 (23):430-4.

12. Radwan AA. Comparing Surgical-Induced Astigmatism through Change of Incision Site in Manual Small Incision Cataract Surgery (SICS). J Clinic Experiment Ophthalmol 2011; 2:161.

13. Pawar VS, Sindal DK. A comparative study on the superior, supero-temporal and the temporal incisions in small incision cataract surgeries for postoperative astigmatism. Journal of Clinical and Diagnostic Research. 2012; 6:1229-32.

How to cite this article?

Kripalini S. H. Comparative study of surgically induced astigmatism: superior versus superotemporal scleral incision performed in rural hospital. Trop J Ophthalmol Otolaryngol.2019;4(2): 86-91. doi: 10.17511/jooo.2019.i02.04 